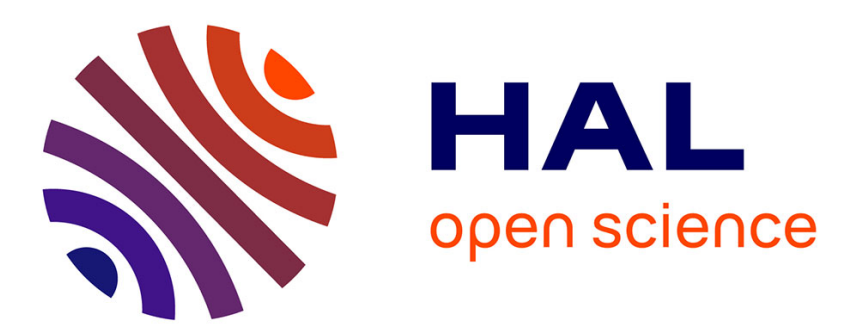

\title{
Instabilities during the growth of dust successive generations in silane-based plasmas
}

Marjorie Cavarroc, Maxime Mikikian, Yves Tessier, Laïfa Boufendi

\section{To cite this version:}

Marjorie Cavarroc, Maxime Mikikian, Yves Tessier, Laïfa Boufendi. Instabilities during the growth of dust successive generations in silane-based plasmas. Physics of Plasmas, 2008, 15, pp.103704. 10.1063/1.2998835 . hal-00331843

\section{HAL Id: hal-00331843 \\ https://hal.science/hal-00331843}

Submitted on 17 Oct 2008

HAL is a multi-disciplinary open access archive for the deposit and dissemination of scientific research documents, whether they are published or not. The documents may come from teaching and research institutions in France or abroad, or from public or private research centers.
L'archive ouverte pluridisciplinaire HAL, est destinée au dépôt et à la diffusion de documents scientifiques de niveau recherche, publiés ou non, émanant des établissements d'enseignement et de recherche français ou étrangers, des laboratoires publics ou privés. 


\title{
Instabilities during the growth of dust successive generations in silane-based plasmas
}

\author{
Marjorie Cavarroc, Maxime Mikikian, ${ }^{*}$ Yves Tessier, and Laïfa Boufendi \\ GREMI, Groupe de Recherches sur l'Energétique des Milieux Ionisés, \\ UMR 6606 CNRS/Université d'Orléans, 14 rue d'Issoudun, BP 6744, 45067 Orléans Cedex 2, France
}

(Dated: September 15, 2008)

\begin{abstract}
Dust growth in silane-based plasmas is known to be a cyclic phenomenon as long as silane is provided. This continuous dust growth leads to an unstable behavior of the complex plasma, characterized by well-defined instabilities. In this paper, a complete study of these instabilities is presented. The electrical analysis is corroborated by an optical one, and high speed video imaging is used to get an insight in the dust cloud behavior. A possible cause of this instability phenomenon is also discussed.
\end{abstract}

PACS numbers: 52.27.Lw,52.35.-g

\section{INTRODUCTION}

Dusty (or complex) plasmas generated in radiofrequency (rf) discharges are widely studied since the 90 's. They are complex systems where new phenomena, arising due to dust grains trapped in the plasma, are observed.

Numerous domains are concerned by dusty plasmas. They can be a source of contamination in industrial processes (silicon deposition [1] or etching [2] plasmas for example). More recently, studies linked to fusion devices have emerged due to the sputtering of the reactor walls $[3,4]$. Dusty plasmas can also be a source of nanoparticles, such as single-crystal silicon nanoparticles [5], that are used to produce nanostructured thin films [6] or to build single electron devices [7]. Another application is the production of analog aerosols of planet atmospheres like Titan [8] or analogs of interstellar dust grains (ISD grains).

In the laboratory, there are several ways to obtain a dusty plasma. Dust particles in the micrometer range are usually injected directly in the plasma. They have the advantage to be easy to visualize in the experiments. However, they have the drawback to experience a significant force due to their non-negligible weight and some phenomena can thus only be observed under microgravity conditions [9]. In the submicrometer range, dust particles are usually grown in the plasma. There are two main ways to grow them: by material sputtering or by polymerization of a reactive gas. Material sputtering is a convenient way to obtain dust grains and is widely used in laboratory experiments [10-13]. Reactive gases such as silane $[1,14-17]$, methane [18-20] or acetylene $[18,19,21,22]$, are used because of their implication in various industrial processes. Moreover, silane-based discharges are often used as "standard systems" to investigate dust formation and growth in plasmas (see for example Refs. [14-16, 23, 24]).

Generally, by using reactive gases or sputtering a

*Electronic address: maxime.mikikian@univ-orleans.fr target, a dense cloud of dust particles trapped in the plasma is obtained. This trapping is due to the negative charge acquired by dust grains that collect free electrons from the plasma [25-28]. Dust formation often induces instabilities of both the plasma and the dust cloud. As an example, in silane-based plasmas, an instability occurs at the beginning of the nanocrystal aggregation in the gas phase $[5,17]$. In the same way, dust particle growth instabilities are observed in sputtering plasmas [29]. These two examples illustrate the strong influence of dust particles on the plasma stability. Dust particles experience various forces, such as electric force, ion drag, neutral drag, gravity or thermophoresis, which are strongly dependent on their size. The balance between those forces determines the dust particle dynamics and the shape of the dust cloud. Usually, the three-dimensional cloud exhibits an egg-shaped dust-free region in the center, called the "void" [9, 12, 13, 30-37]. This void region seems to be due to a balance between an inward electric force and an outward ion drag force. Moreover, the void region is also often linked to dust particle growth in the discharge. Several cases of dust growth inside the void region have already been reported $[13,34,37]$. On top of it, self-excited oscillations in the void size can occur such as the "heartbeat" instability reported in Refs. [31, 36, 38-40].

In this paper we report on self-excited instabilities occurring during the growth of dust successive generations in $\mathrm{Ar} / \mathrm{SiH}_{4}$ low pressure plasmas. Electrical and optical diagnostics are correlated to characterize these instabilities. They are strongly suspected to be instabilities of the void region. Their possible cause is discussed at the end of the paper.

\section{EXPERIMENTAL SETUP}

The experimental setup we use has already been described in detail in previous papers (see for example Ref. [41]). The rf discharge is produced in a grounded cylindrical plasma box (13 cm inner diameter and $3.3 \mathrm{~cm}$ for inter-electrode distance), enclosed in a vacuum vessel. A 


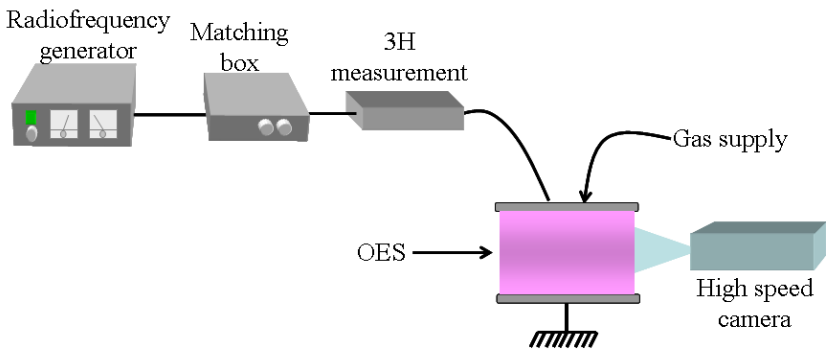

FIG. 1: (Color online) Sketch of the experimental setup.

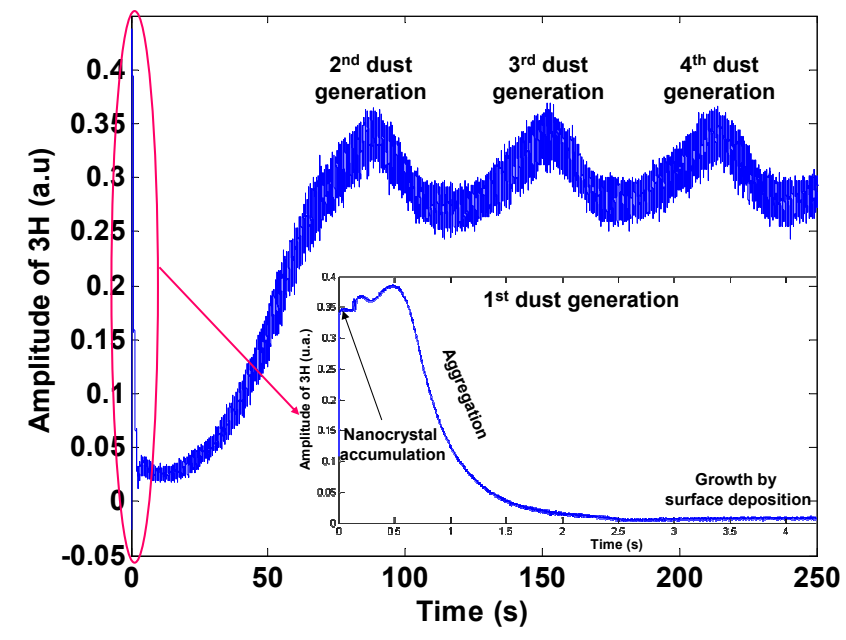

FIG. 2: (Color online) Time-evolution of the third harmonic of the discharge current amplitude during dust particle growth in an argon-silane plasma for different time-scales.

\section{RESULTS}

shower-head type electrode ensures a homogeneous gas nected to a $13.56 \mathrm{MHz}$ radiofrequency generator through a matchbox including a blocking capacitor. The power is usually varied from 0 up to 20 Watts. To perform the following observations, the setup was equipped with a high-speed camera and an optical emission spectrometer both focused in the plasma center. A simple sketch of the setup is given in Fig. 1.

The main diagnostics we use is an electrical one based on the time evolution of the amplitude of the third harmonic of the discharge current $(3 \mathrm{H})$ and the amplitude of the self-bias voltage $\left(\mathrm{V}_{d c}\right)[42]$. Indeed the presence of dust grains affects many of the physical properties of the plasma (electron density and temperature, electric field, impedance, ...) and induces modifications in the electrical characteristics of the discharge. This diagnostics has been shown to be able to follow the particle formation and growth in different chemistries such as silane and methane based ones. In a dust-free plasma, the amplitude of $3 \mathrm{H}$ and $\mathrm{V}_{d c}$ remains constant in time. When a reactive gas (silane, methane...) is added, i.e. in a dust forming plasma, $\mathrm{V}_{d c}$ and $3 \mathrm{H}$ show a time evolution due to dust particle formation and growth. The main formation steps can be clearly identified thanks to this electrical diagnostics (Fig. 2) [5, 42].

The current and voltage probes are inserted between the matchbox and the powered electrode. The curves are visualized on a Tektronix scope DPO 7254 (2.5 GHz bandwidth and $40 \mathrm{GS} / \mathrm{s}$ ) and the results are recorded via a computer. Most of the following experiments have been performed in these "standard" conditions: $30 \mathrm{sccm}$ of argon flow rate and $1.2 \mathrm{sccm}$ of silane flow rate, leading to a total pressure around $12 \mathrm{~Pa}$. The reference for injected power is 10 Watts corresponding to about 400 Volts peak-to-peak. Experiments are performed at room temperature.

\section{A. Dust particle successive generations}

In previous experimental and theoretical works [4244 , the way dust particles grow in an argon/silane low pressure rf plasma has been brought to the fore. The growth of the first generation has been shown to be a four step process occurring in the gas phase: nanocrystal growth (2-3 nm in diameter) from molecular species, accumulation phase, aggregation phase, and growth by deposition of the plasma species on the dust grain surface (see Fig. 2). Dust particle formation and growth is a continuous phenomenon: as long as silane precursors are provided, new generations of dust particles are formed in the discharge $[37,45]$. The phenomenon we study is located around a few tens of seconds after plasma ignition, during the growth of dust successive generations in the plasma.

Successive generations of dust particles can be monitored thanks to the $V_{d c} / 3 \mathrm{H}$ diagnostics. They appear as quasi-sinusoidal low-frequency oscillations of the signal, with a period of the order of typically one minute. From the time evolution of $3 \mathrm{H}$ in Fig. 2 we can distinguish: (insert) nanocrystal formation and accumulation, aggregation instability ([5, 17]), nanocrystal aggregation and growth by surface deposition, and in the main part of Fig. 2, second to fourth dust particle generations. The decrease of $3 \mathrm{H}$ corresponds to a decrease of the electron density: this can be explained both by the presence of big dust particles attaching lots of electrons, or by numerous little dust particles that could produce the same effect. The increase of $3 \mathrm{H}$ corresponds to an increase of the electron density, meaning that less electrons are attached by dust particles: big dust particles 
could be expelled from the plasma, or the density of smaller dust particles is low. All classical parameters affecting dust particle formation have an influence on the time-period of these oscillations. As an example, when gas temperature is increased, dust particle formation is delayed $[17,46]$ and the time-period of these oscillations can rise above several minutes.

Dust particle growth during successive generations has been shown to be a three-step process [37]. The formation and growth take place in a void region in the plasma center, following a cycle. First, the ionization rate increases in the void region and new dust particles start to grow and to attach free electrons. They push away bigger dust grains. Then the new dust generation fills the whole void region. Finally, a new void opens in the dust cloud, favoring the formation of a new dust generation [37].

\section{B. Successive Generation Instabilities (SGI)}

\section{Electrical characterization of the SGI}

By performing a global Fast Fourier Transform (FFT) of the $3 \mathrm{H}$ signal during the oscillations due to dust particle growth (Fig. 3(a)), we can bring to the light the unstable behavior of the signal (see Fig. 3(b)). The global FFT exhibits a broadband spectrum typically comprised between 30 and $90 \mathrm{~Hz}$. As an example, Fig. 3(b) shows a spectrum ranging from 30 to 70 $\mathrm{Hz}$ with some identifiable frequencies. To refine our observations, we performed a time-resolved FFT of the same signal and we obtain a spectrogram as the one in Fig. 3(c). The first observation is that these Successive Generation Instabilities (SGI) are self-excited (no external excitation) and last as long as the plasma is on. Typically, these spectrograms exhibit an alternation of very ordered phases with low frequencies (between 40 and $60 \mathrm{~Hz}$ ) and less ordered phases with higher frequencies. As an example, Fig. 3(c) shows a spectrum ranging from 52 to $60 \mathrm{~Hz}$. From the dust formation cycle detailed in Ref. [37], we can assume that highly-ordered phases roughly correspond to the dust particle formation for each new generation. During theses phases, the SGI frequency linearly decreases on an interval of about 10 Hz. Still referring to Ref. [37], we can assume that less-ordered phases roughly correspond to dust expelling from the plasma. During these phases, the frequency is not well-defined, but is globally higher than the one of the highly-ordered phases. The observed frequencies still remains under $100 \mathrm{~Hz}$ in the parameter range we explored. Figure 4 shows a transition from a less-ordered phase to a highly-ordered one in the $3 \mathrm{H}$ signal. In this figure, it clearly appears that the oscillations are not well-defined in the left-hand part and that they have a small amplitude, while they are quasi-sinusoidal on the right-hand part with a greater amplitude. An
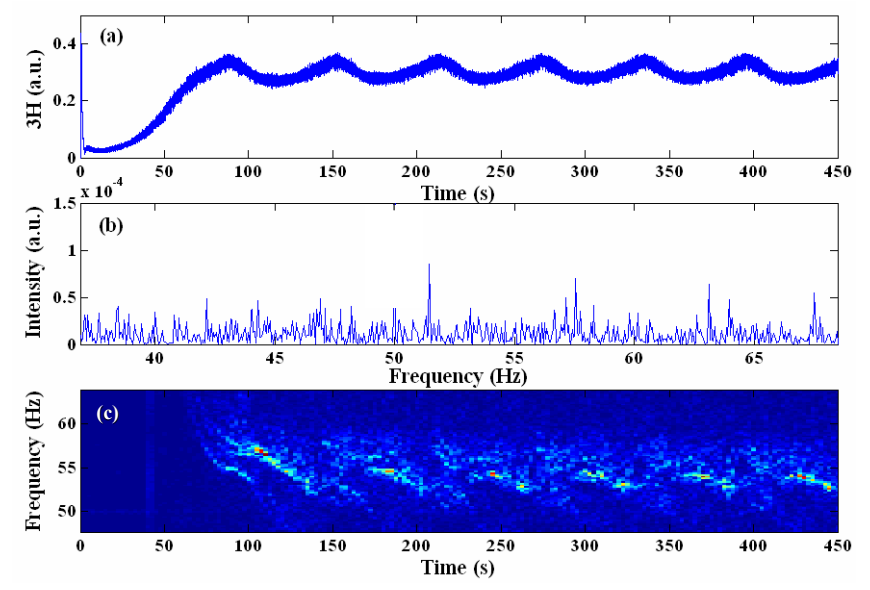

FIG. 3: (Color online) (a)Time-evolution of the third harmonic of the discharge current during dust particle successive generations in an argon-silane plasma (b) Global FFT of the $3 \mathrm{H}$ signal (c) Spectrogram of $3 \mathrm{H}$ during the successive generation instabilities (color scale from dark blue to red).

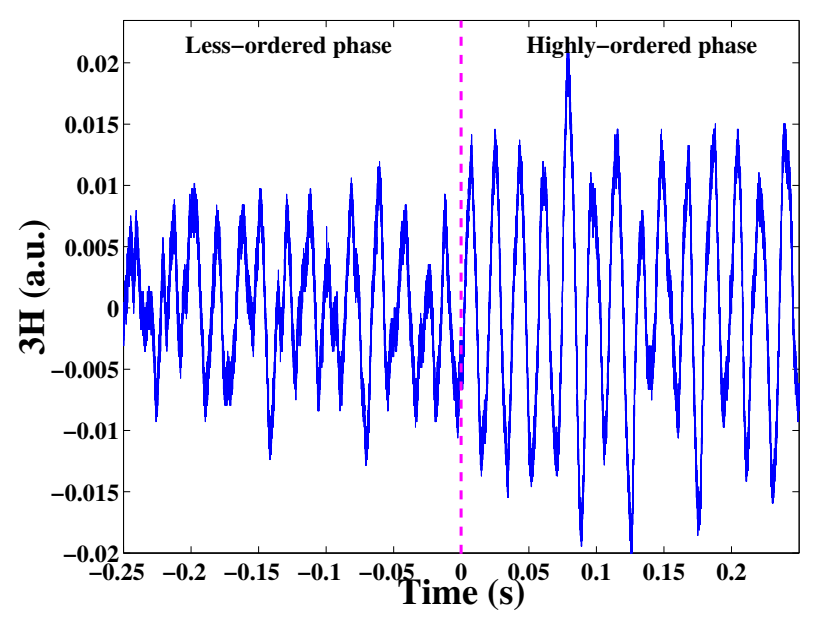

FIG. 4: (Color online) Transition from a less-ordered phase to a highly-ordered phase on $3 \mathrm{H}$ during the SGI.

estimation of the oscillation frequency on the two parts of this signal gives a frequency around $61 \mathrm{~Hz}$ for the less-ordered part compared to a frequency around $56 \mathrm{~Hz}$ for the highly-ordered one.

The beginning of the SGI occurs generally a few seconds after the plasma ignition. The signal starts to oscillate spontaneously as can be seen around $2.3 \mathrm{~s}$ in the insert of Fig. $5(\mathrm{t}=0 \mathrm{~s}$ is the plasma ignition and the arrow marks the onset of the instabilities). The setting-up of the instabilities appears as an increase in the oscillation amplitude over about $40 \mathrm{~s}$ (see Fig. 5). The spectrogram of the electrical signal at the instability onset exhibits a very complex scheme with several frequency-branches. Figure 6 shows the time evolution of the electrical signal 


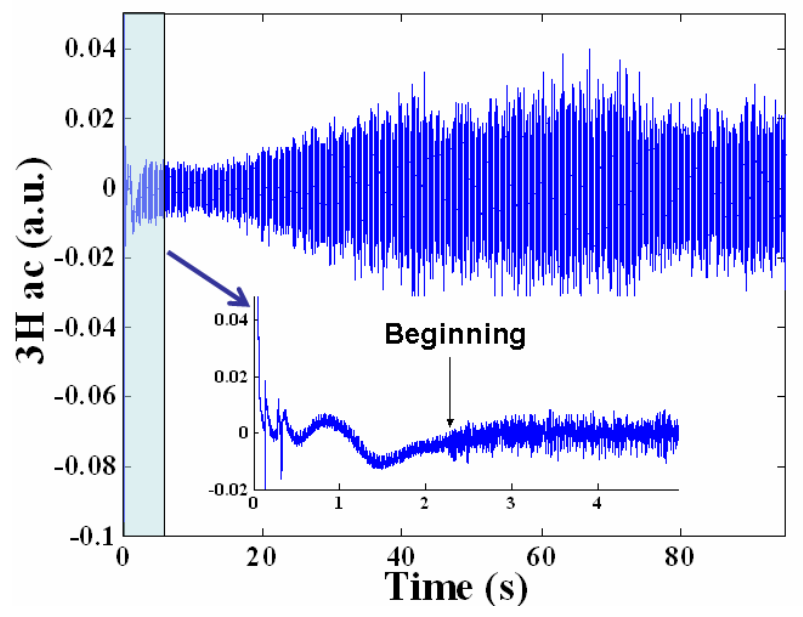

FIG. 5: (Color online) Time evolution of 3H (alternative component) at SGI beginning. Insert: zoom on the 5 first seconds.

frequencies during the first two hundreds seconds of the experiment. The SGI beginning is evidenced around $2 \mathrm{~s}$ through the appearance of a nearly vertical colored line indicating that the signal starts to oscillate. This observation is in accordance with the results deduced from Fig. 5. Afterwards, the instabilities develop in a very complex way. Several frequencies are brought to the fore by the FFT. First, only two frequencies around $28 \mathrm{~Hz}$ and $78 \mathrm{~Hz}$ can be seen between 2 and $10 \mathrm{~s}$ roughly (arrows in Fig. 6). Then the two frequencies start to evolve: increasing for the lowest one and decreasing for the highest one. From around $\mathrm{t}=50 \mathrm{~s}$, five branches can be evidenced. Indeed, the signal clearly oscillates but the time duration in between peaks is highly fluctuating. This fluctuation consists of a succession of short phases with different frequencies but also in strong variations of the time interval in between successive peaks. The period between two successive peaks can be different from the one between the next two successive peaks. This strong frequency fluctuation on very short time scales (as a given frequency can only concerns two peaks) is responsible of the final behavior with multiple branches. One of the very important points is that the signal frequency fluctuates but tends to return always close to some defined frequencies drawing these branches. Thus, the signal is not random but seems to follow a defined behavior. The two lowest branches (starting around $32 \mathrm{~Hz}$ and $38 \mathrm{~Hz}$ ) tend to meet in one branch around $30 \mathrm{~Hz}$, between 100 and $110 \mathrm{~s}$. This new branch disappears quickly (between 130 and $140 \mathrm{~s}$ ). The three highest branches (starting around $45 \mathrm{~Hz}, 55$ $\mathrm{Hz}$ and $65 \mathrm{~Hz}$ ) tend to meet in a unique branch (around $40 \mathrm{~Hz}$ ), which persists as long as the plasma is on. If we look carefully at this last frequency branch (around 120 s in Fig. 6), we can determine that the SGI are mainly characterized by two very close frequencies (around 36 and $40 \mathrm{~Hz}$ in this case) that are hard to discern one from the other. These two close frequencies could explain the

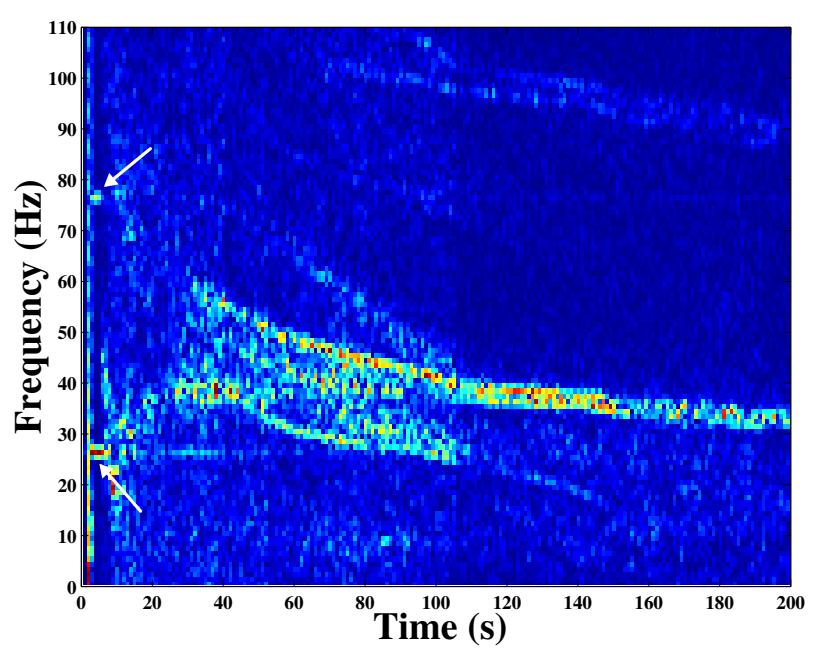

FIG. 6: (Color online) Spectrogram of the SGI beginning.

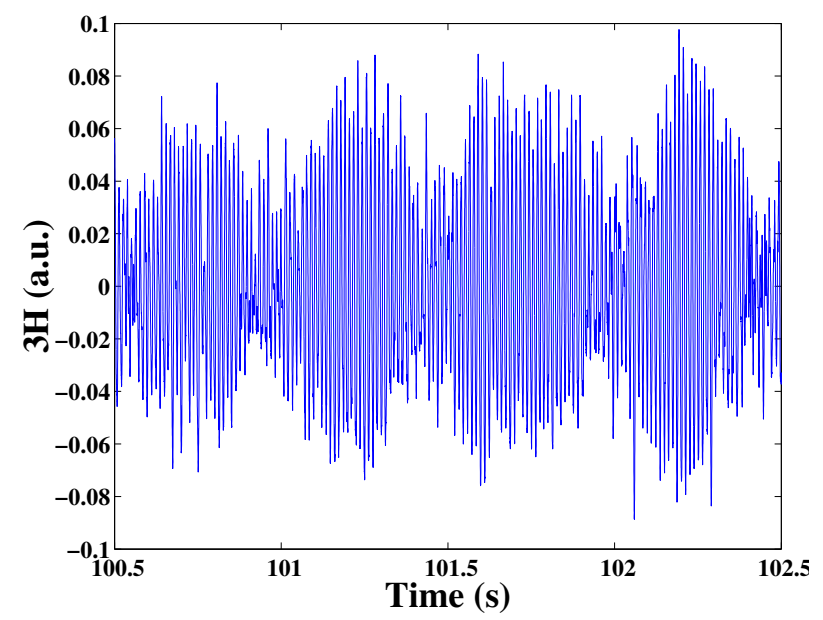

FIG. 7: (Color online) Modulation of 3H during the SGI.

noticeable modulation of the electrical signal that can be observed in Fig. 7. The modulation frequency $(2 \mathrm{~Hz})$ indeed corresponds to $\left(f_{2}-f_{1}\right) / 2$ with $f_{2} \simeq 40 \mathrm{~Hz}$ and $f_{1} \simeq 36 \mathrm{~Hz}$. The complex scheme described above does not depend on experimental parameters. It is the same whatever the conditions and is very reproducible. Only the frequencies can slightly change from one run to another. It can bring to mind some other complex schemes of instabilities observed in the PKE-Nefedov experiment $[29,38]$.

\section{Optical characterization of the SGI}

A direct comparison between the FFT of the $3 \mathrm{H}$ signal and the one of the time evolution of the line at 750.38 $\mathrm{nm}$ of $\operatorname{ArI}\left(\mathrm{I}_{750.38}\right)$ (see Fig. 8) recorded simultaneously during dust successive generations, shows that these two 

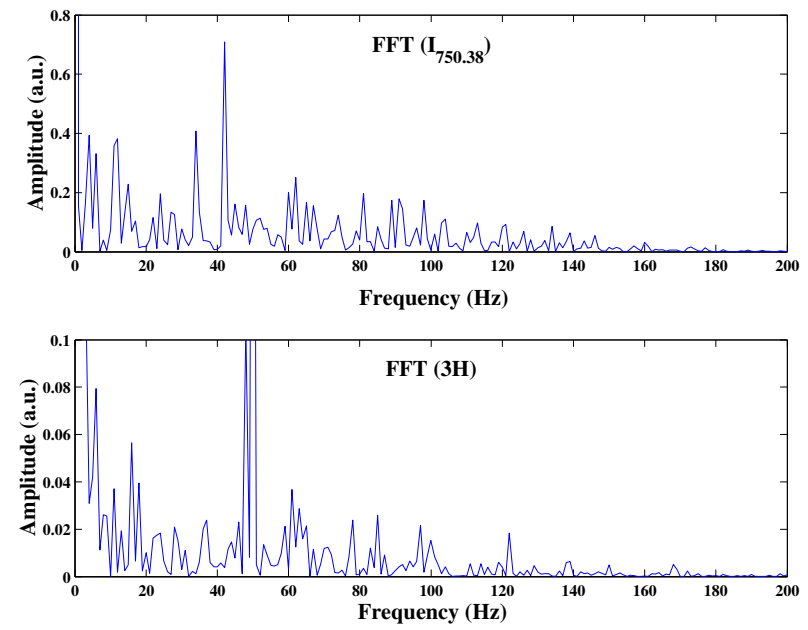

FIG. 8: (Color online) FFT spectra of $3 \mathrm{H}$ and Ar line (at $750.38 \mathrm{~nm})$.

spectra are very similar. This result underlines that the SGI are not an artefact due to the power coupling system for example.

The electrical characterization of the SGI is thus corroborated by an optical one. In order to go further in the investigation of the instability behavior, several movies were recorded during the SGI, using a high speed camera (1789 frames per second (fps)). The global emission (glow) of the plasma was recorded over 4000 frames corresponding to $2.25 \mathrm{~s}$ approximately. By looking at the integrated glow over each frame as a function of time (Fig. 9(a)), we get signals very similar to the ones obtained thanks to the electrical measurements. Moreover, the FFT spectrum of these optical signals is comparable to the one of electrical signals. It generally exhibits a broadband spectrum comprised between 30 and $90 \mathrm{~Hz}$. As an example, Fig. 9(b) shows a spectrum extracted from one of the movies, with typical frequencies comprised between 50 and $90 \mathrm{~Hz}$. Due to experimental constraints, synchronization between the $3 \mathrm{H}$ signal and the recorded movies has not been possible. As the SGI are a very reproducible phenomenon in qualitative terms, we compared data that do not proceed from the same experiment. Moreover, the $3 \mathrm{H}$ diagnostic is integrated over all the plasma volume while optical diagnostics such as OES or glow recording are spatially resolved. This can explain the small discrepancies observed in Figs. 8 and 9 (b).

Figure 10 shows a typical frame extracted from a movie. The dark blue part corresponds to the plasma box, while the part inside the circle (in false colors, red standing for high intensities and blue for low ones) corresponds to the plasma glow emission. The center of the circle hardly corresponds to the plasma center. In this figure, we can clearly identify an area in red, at the top of the circle, corresponding to a higher ionization rate. This particular area has been inferred to be a void re-
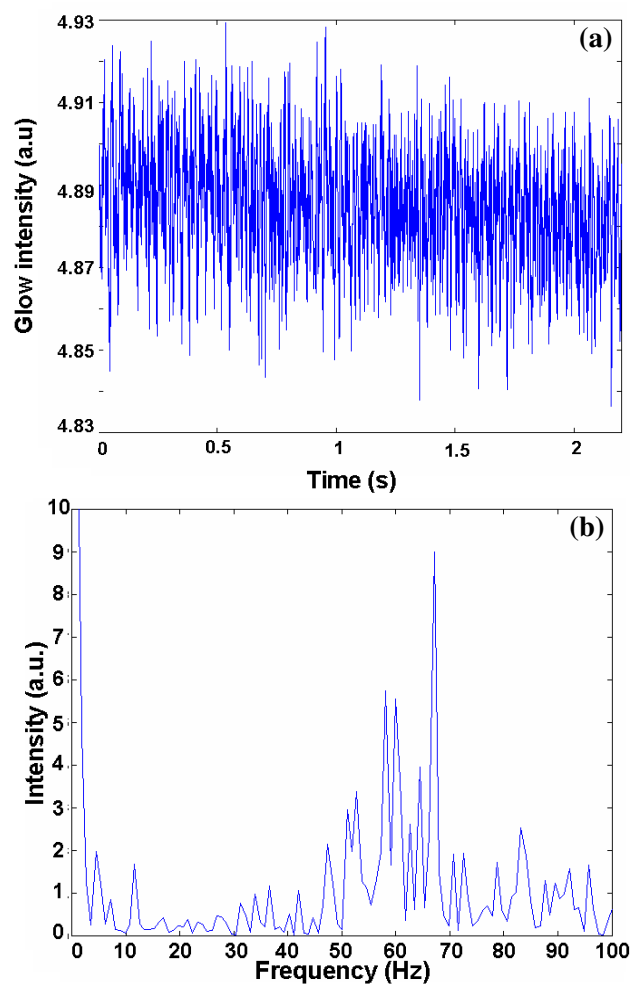

FIG. 9: (Color online) (a) Time-evolution of the plasma glow with (b) its corresponding FFT, during the SGI.

gion in the dust cloud [37]. In order to follow the void evolution during the SGI, we chose to extract the central column and the line number 75 of each frame of the movies. The line 75 profile is much more representative than the central one due to the off-centered void (the void boundary often crosses the line 75 while it seldom crosses the central one [37]). Figures 11(a) and 11(b) give the time evolution of the central column profile and the line 75 profile. In order to get a better understanding, the time evolution of the integrated value of the column (line) is superimposed on the obtained matrix. These two profiles bring to the fore an intensity oscillation of the area of maximum ionization in the plasma. The obtained signals are very close to the ones obtained thanks to the electrical diagnostics. The main frequencies are the same. By exploring the column and line profiles over several movies, we can find back the succession of highlyordered and less-ordered phases. Some strong intensity decreases (over one or two frames) of the central region can even be evidenced. They are not fully explained yet.

\section{Sensitivity to parameters}

Various parameters such as injected power, pressure, silane amount and gas temperature, have been varied in the discharge in order to get an insight in the SGI sensitivity to parameters. Compared to the aggregation in- 


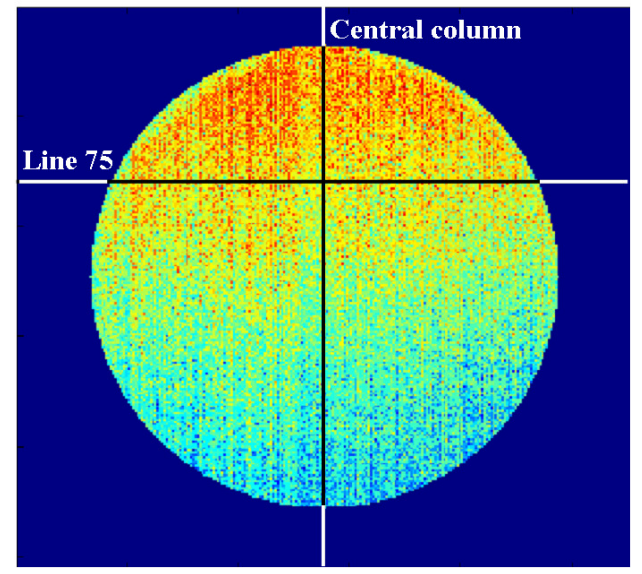

FIG. 10: (Color online) Typical frame extracted from a movie. Blue stands for low intensity, and red for high intensity. The zero of the $y$-axis is at the top.
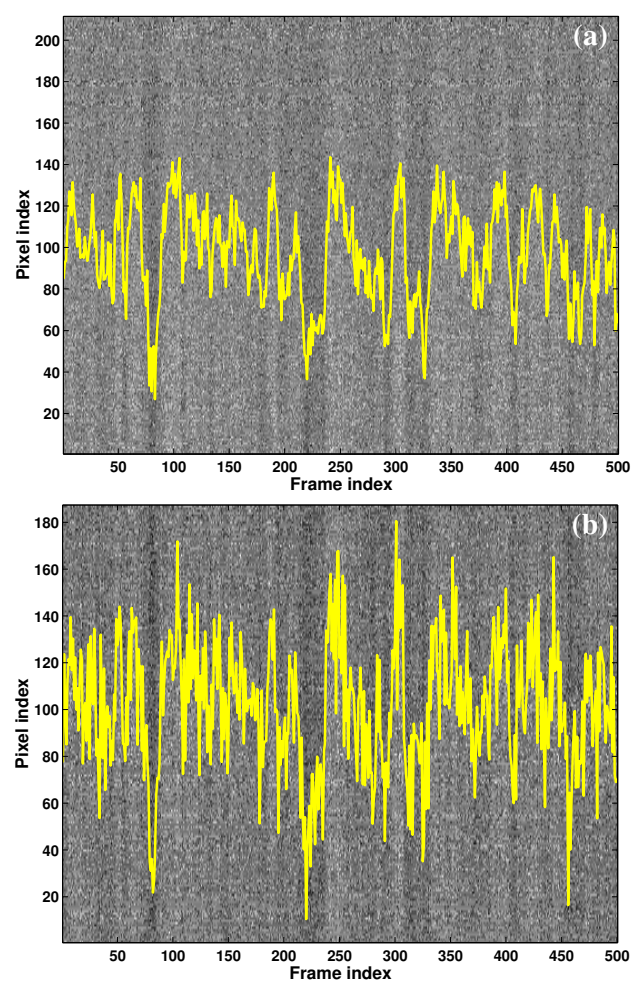

FIG. 11: (Color online) (a) Column and (b) line profiles of the plasma glow during the SGI, the superimposed yellow curve is the time evolution of the integrated value of the column (line).

stability observed in the same $\mathrm{Ar} / \mathrm{SiH}_{4}$ plasmas [5], the SGI are globally not very sensitive to experimental parameters. As a matter of fact, no case of disappearance of the instabilities has been observed by modifying the experimental conditions. As soon as a second dust particle generation starts to grow in the plasma, the instabilities arise. It seems to be an intrinsic characteristic of
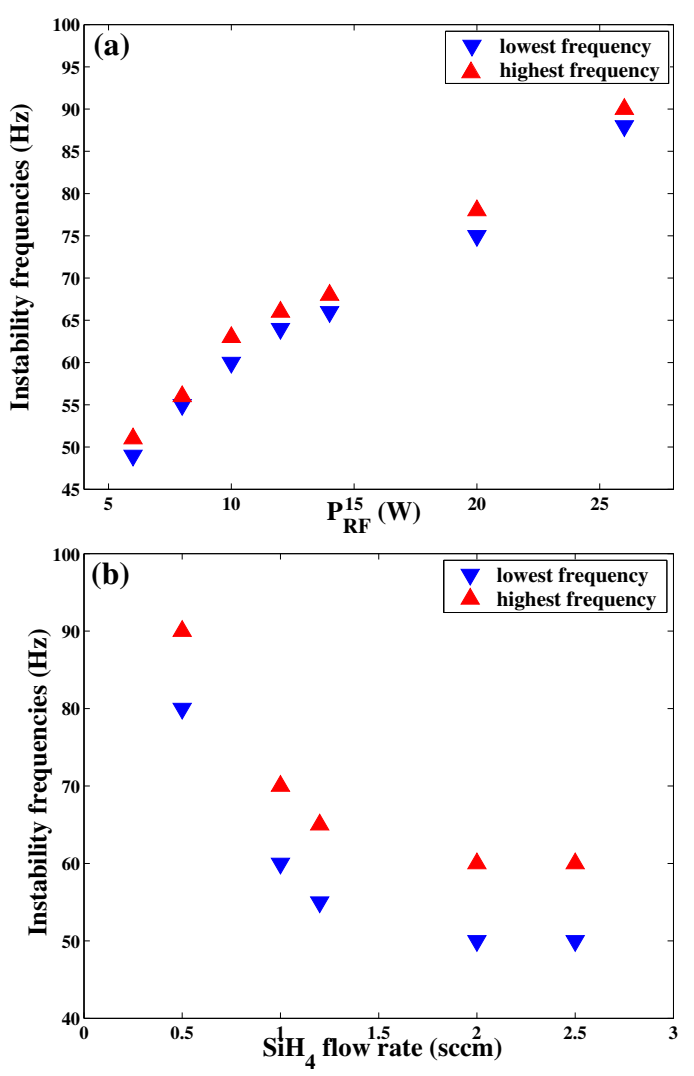

FIG. 12: (Color online) Evolution of the SGI frequencies for different (a) injected powers and (b) silane flow rates.

dust successive generations in $\mathrm{Ar} / \mathrm{SiH}_{4}$ low-pressure plasmas. Nevertheless, some slight modifications in the SGI frequencies have been observed, depending on the experimental conditions. The frequency of the instabilities is quite difficult to determine. Actually, as we showed from the analysis of Fig. 6, the fully developed SGI are characterized by two close frequencies (the highest one and the lowest one). We chose to use these two frequencies (measured between 100 and $150 \mathrm{~s}$ after plasma ignition, depending on the parameters) to evaluate the SGI sensitivity to experimental parameters. When the injected rf power is increased, the frequencies of the instability tend to increase as can be seen in Fig. 12(a). This behavior is the same as the one of the aggregation instability studied in Ref. [17]. Furthermore the instabilities begin earlier for higher injected powers as expected from our experience $[5,17]$. On the contrary, these same frequencies tend to decrease when the silane flow rate in the discharge is increased (see Fig. 12(b)). The gas temperature effects are even more difficult to border. It seems to have no effect on the frequency of the highly-ordered phases while it seems that the frequency of the less-ordered phases increases when decreasing gas temperature. Furthermore, pressure does not seem to have any outstanding effect on the instability behavior in the pressure range we explored (from 0.1 to 1 mbar). We can also notice that both frequencies evolve with parameters, but the gap between 
the lowest and the highest frequencies is almost constant when varying a single control parameter(between 2 and $10 \mathrm{~Hz}$, depending on experimental conditions).

\section{CONCLUSION}

As we showed in the description of the SGI, these instabilities are closely linked to the formation and growth of dust particle successive generations. In a previous paper [37], we showed that the formation and growth of dust successive generations in $\mathrm{Ar} / \mathrm{SiH}_{4}$ low pressure plasmas is a cyclic phenomenon, involving three steps, which takes place in a void region in the dust cloud. Schematically, new dust generations grow in the void, pushing previously formed and bigger dust particles toward the plasma edge. The SGI highly-ordered phases correspond to new dust formation, while the SGI less-ordered ones correspond to the expelling of bigger dust particles toward the plasma edge. As the formation of dust particles is nearly continuous in silane-based discharges, the SGI last during the whole duration of the plasma which is in consequence constantly unstable.

The formation of a new dust generation highly modifies the ionization rate, and thus the forces, in the void region. The equilibrium between the ion drag and the electric force becomes then unbalanced, leading to an oscillation of the void region. A very similar phenomenon has also been observed in the PKE-Nefedov experiment, where the void region tends to be unstable when new dust generations grow inside [47].

\section{ACKNOWLEDGMENT}

ESA and Kayser-Threde GmbH are acknowledged for providing the high-speed camera system in the framework of the IMPACT program.
[1] R. Roth, K. Spears, G. Stein, and G. Wong, Appl. Phys. Lett. 46, 253 (1985).

[2] G. S. Selwyn, J. Singh, and R. S. Bennett, J. Vac. Sci. Technol. A 7, 2758 (1989).

[3] J. Winter, Plasma Phys. Control. Fusion 40, 1201 (1998).

[4] C. Arnas, C. Dominique, P. Roubin, C. Martin, C. Brosset, and B. Pégourié, J. Nucl. Mat. 353, 80 (2006).

[5] M. Cavarroc, M. Mikikian, G. Perrier, and L. Boufendi, Appl. Phys. Lett. 89, 013107 (2006).

[6] P. Roca i Cabarrocas, N. Chaabane, A. Kharchenko, and S. Tchakarov, Plasma Phys. Control. Fusion 46, B235 (2004).

[7] S. Tiwari, F. Rana, H. Hanafi, A. Hartstein, and E. F. Crabb, Appl. Phys. Lett. 68, 1377 (1996).

[8] C. Szopa, G. Cernogora, L. Boufendi, J. J. Correia, and P. Coll, Planet. Space Sci. 54, 394 (2006).

[9] G. Morfill, H. Thomas, U. Konopka, H. Rothermel, M. Zuzic, A. Ivlev, and J. Goree, Phys. Rev. Lett. 83, 1598 (1999).

[10] G. S. Selwyn, J. S. McKillop, K. L. Haller, and J. J. Wu, J. Vac. Sci. Technol. A 8, 1726 (1990).

[11] B. Ganguly, A. Garscadden, J. Williams, and P. Haaland, J. Vac. Sci. Technol. A 11, 1119 (1993).

[12] G. Praburam and J. Goree, Phys. Plasmas 3, 1212 (1996).

[13] M. Mikikian, L. Boufendi, A. Bouchoule, H. M. Thomas, G. E. Morfill, A. P. Nefedov, V. E. Fortov, and the PKENefedov team, New J. Phys. 5, 19 (2003).

[14] Y. Watanabe, M. Shiratani, Y. Kubo, I. Ogawa, and S. Ogi, Appl. Phys. Lett. 14, 1263 (1988).

[15] A. Bouchoule, A. Plain, L. Boufendi, J. P. Blondeau, and C. Laure, J. Appl. Phys. 70, 1991 (1991).

[16] A. Howling, C. Hollenstein, and P.-J. Paris, Appl. Phys. Lett. 59, 1409 (1991).

[17] M. Cavarroc, M. C. Jouanny, K. Radouane, M. Mikikian, and L. Boufendi, J. Appl. Phys. 99, 064301 (2006).

[18] C. Deschenaux, A. Affolter, D. Magni, C. Hollenstein, and P. Fayet, J. Phys. D: Appl. Phys. 32, 1876 (1999).

[19] S. Hong, J. Berndt, and J. Winter, Surf. Coat. Technol. 174-175, 754 (2003).

[20] J. Pereira, V. Massereau-Guilbaud, I. Géraud-Grenier, and A. Plain, J. Appl. Phys. 103, 033301 (2008).

[21] K. de Bleecker, A. Bogaerts, and W. Goedheer, Phys. Rev. E 73, 026405 (2006).

[22] J. Berndt, E. Kovacevic, V. Selenin, I. Stefanovic, and J. Winter, Plasma Sources Sci. Technol. 15, 18 (2006).

[23] C. Böhm and J. Perrin, J. Phys. D: Appl. Phys. 24, 865 (1991).

[24] E. Stoffels, W. Stoffels, G. Kroesen, and F. de Hoog, J. Vac. Sci. Technol. A 14, 556 (1996).

[25] B. Walch, M. Horanyi, and S. Robertson, IEEE Trans. Plasma Sci. 22, 97 (1994).

[26] A. Melzer, T. Trottenberg, and A. Piel, Phys. Lett. A 191, 301 (1994).

[27] C. Arnas, M. Mikikian, and F. Doveil, Phys. Rev. E 60, 7420 (1999).

[28] L. Couëdel, M. Mikikian, L. Boufendi, and A. A. Samarian, Phys. Rev. E 74, 026403 (2006).

[29] M. Mikikian, M. Cavarroc, L. Couëdel, and L. Boufendi, Phys. Plasmas 13, 092103 (2006).

[30] J. Dorier, C. Hollenstein, and A. Howling, J. Vac. Sci. Technol. A 13, 918 (1995).

[31] J. Goree, G. E. Morfill, V. N. Tsytovich, and S. V. Vladimirov, Phys. Rev. E 59, 7055 (1999).

[32] M. R. Akdim and W. J. Goedheer, Phys. Rev. E 65, 015401 (2001).

[33] K. Avinash, Phys. Plasmas 8, 2601 (2001).

[34] J. Schauer, S. Hong, and J. Winter, Plasma Sources Sci. Technol. 13, 636 (2004).

[35] M. Kretschmer, S. A. Khrapak, S. K. Zhdanov, H. M. Thomas, G. E. Morfill, V. E. Fortov, A. M. Lipaev, V. I. Molotkov, A. I. Ivanov, and M. V. Turin, Phys. Rev. E 71, 056401 (2005).

[36] S. V. Vladimirov, V. N. Tsytovich, and G. E. Morfill, 
Phys. Plasmas 12, 052117 (2005).

[37] M. Cavarroc, M. Mikikian, Y. Tessier, and L. Boufendi, Phys. Rev. Lett. 100, 045001 (2008).

[38] M. Mikikian and L. Boufendi, Phys. Plasmas 11, 3733 (2004).

[39] M. Mikikian, L. Couëdel, M. Cavarroc, Y. Tessier, and L. Boufendi, New J. Phys. 9, 268 (2007).

[40] M. Mikikian, M. Cavarroc, L. Couëdel, Y. Tessier, and L. Boufendi, Phys. Rev. Lett. 100, 225005 (2008).

[41] L. Boufendi, A. Plain, J. P. Blondeau, A. Bouchoule, C. Laure, and M. Toogood, Appl. Phys. Lett 60, 169 (1992).

[42] L. Boufendi, J. Gaudin, S. Huet, G. Viera, and M. Dudemaine, Appl. Phys. Lett. 79, 4301 (2001).

[43] A. A. Fridman, L. Boufendi, T. Hbid, B. V. Potapkin, and A. Bouchoule, J. Appl. Phys. 79, 1303 (1996).

[44] M. Shiratani, T. Fukuzawa, and Y. Watanabe, Jpn. J. Appl. Phys. 38, 4542 (1999).

[45] A. Melzer, A. Homann, A. Piel, V. A. Schweigert, and I. V. Schweigert, AIP Conference Proceedings 446, 168 (1998).

[46] L. Boufendi, J. Hermann, A. Bouchoule, B. Dubreuil, E. Stoffels, W. W. Stoffels, and M. L. deGiorgi, J. Appl. Phys. 76, 148 (1994).

[47] M. Mikikian, L. Boufendi, and A. Bouchoule, Proceedings of the $30^{\text {th }}$ EPS Conference on Plasma Physics and Controlled Fusion, St Petersburg, 2003, edited by R. Koch and S. Lebedev (European Physical Society, Petit-Lancy, 2003), Vol. 27A, p. O-3.1B. 